\title{
The Effect of Group Training on Theory of Mind of Male Clients of Bahar Outpatient Addiction Treatment Center
}

\author{
Gholam Hossein Javanmard \\ Psychology Department, Payame Noor University (PNU), Iran
}

Email address:

javanmardhossein@gmail.com

\section{To cite this article:}

Gholam Hossein Javanmard. The Effect of Group Training on Theory of Mind of Male Clients of Bahar Outpatient Addiction Treatment Center. American Journal of Applied Psychology. Vol. 6, No. 1, 2017, pp. 1-5. doi: 10.11648/j.ajap.20170601.11

Received: August 10, 2016; Accepted: August 20, 2016; Published: March 1, 2017

\begin{abstract}
The theory of mind ability underlies the human ability to make complex social interactions. In this study, differences in the theory of mind ability of people with substance dependence and a normal group, and the effect of group training of this ability on addicted people were assessed. In this research, causal-comparative and semi experimental with a pretest and posttest method with a control group were used. For this purpose, 36 male subjects who referred for outpatient addiction treatment center and 36 healthy male people were selected and Baron-Chohen's Reading the Mind in the Eyes Test was administrated in both groups. The group of drug dependence was divided into two groups of 18 people as experimental and control groups. For experimental group, group training sessions were conducted in 24 sessions. Ultimately, test of mind reading was administered as post-test to both groups. Data were analyzed by t-test and one-way analysis of covariance. Data analysis showed that both healthy and dependent groups had significant differences in theory of mind $(\mathrm{P}<0 / 05)$. Moreover, after theory of mind training implementation, along with other current treatments, experimental group scores differed significantly from the control group $(\mathrm{P}<0 / 05)$. The study indicated that the group training increased the theory of mind scores, so, this kind of training could be the part of therapy of individuals with a substance abuse disorders.
\end{abstract}

Keywords: Mind Reading, Addiction, Group Training, Theory of Mind

\section{Introduction}

Theory of mind is one aspect of social cognition. The phrase theory of mind was first used by Premack and Woodruff [1], as two anthropologists and psychologists. They asked the question of does the chimpanzees have a theory of mind? Theory of mind refers to the ability to attribute mental states (e.g., thoughts, beliefs, desires, and intentions) to individuals (self and others). The slang meaning of theory of mind is the ability to tell what people think and perceive. This theory, as one aspect of social cognition, deals with thinking about mental states, such as beliefs or desires and presumption about beliefs and opinions [2]. This skill has much importance since social performance depends on social relationship management. Essential skills for theory of mind include social symptoms recognition, social knowledge, emotional processing, attention, memory, working memory, and decision making [3]. Theory of mind basis is the ability to use our own emotional states to create theories about desires, motivations, and intentions of others. Therefore, the ability of the theory building about others mental content is not based on the awareness of others thoughts, but based on assumptions about their nature and objectives [4].

Brain, among its amazing capacities, has the ability to see the inner causes of others' physical actions such as thoughts and intentions. In the other words, human has a theory of mind to understand and interpret the outward actions of others. Theory of mind in its complete form is unique to human beings. Some believe that this ability was created more than ten thousand years ago, when social environments became increasingly sophisticated and evolutionary pressure was cumulatively applied on the previous human's mind [5]. Increasing social groups required increasing processing capacities in high levels. This indicates a positive relationship between the size of the group and neocortex size of different types of primates [6].

It is said that, theory of mind develops gradually by emerging of spindle cells from four months [7]. But until four or five years, the child couldn't have beliefs about another person's beliefs [8]. It means that about 4 to 5 years, 
a change occurs in children's understanding of mind and they will be able to respond to the theory of mind tests [9]. Generally, it seems that three types of cells are important in the development of theory of mind; mirror neurons, spindle neurons, and spatial somatosensory neurons. Neuronal circuit involved in social attachment is reward circuit which consisted of ventral tegmental area, nucleus accumbens, pallidum, thalamus, and prefrontal-cingulate cortex. In general, in supporting social mind theory which is more comprehensive than theory of mind [10], it has been attributed to a hormonal system, too. This hormonal system is mainly focused to Oxytocin and Vasopressin produced in hypothalamus, stored in the posterior pituitary, and released in certain circumstances [11].

Theory of mind is very important not only because of its interesting topic in the field of interdisciplinary such as social neuroscience, but also due to opening new way to study clinical status. According to theory of mind, in examining some mental disorders, it becomes clear that the element of relation to the other or the way of others' mind interpretation towards to own make the main core of the disorder. This is most clearly seen in delusional disorders. In the delirium of love, a person, more likely a female, believes that she is fascinated by a man of a higher social class, but for some reasons, avoids overt expressions of her love. In fact, in this example, the person focuses to the theory of mind, although far from reality, about other person. Especially in delusional disorder, at least we're witnessing so much of deliriums which are related to the theory of mind. This disorder in theory of mind can be followed in other disorders such as schizophrenia, autism, and bipolar disorder. In substance dependence disorders, we also observe the collapse of social relationships in addicts along with other damages. Drug dependence is a relapsing chronic disorder with three characteristics: 1) force to search and substance abuse, 2) lack of control to limit the consumption, and 3) the incidence of negative emotional states (e.g., boredom, anxiety, and restlessness) when there is no access to the drugs [12]. Addiction is a disorder with biological-psychological-social dimensions. Addiction, as a social damage and disorder, occurs either by the effect of mental disorders and social damage or leads to psychological and mental disorders and also other social damages. Because of this and more other reasons, addiction can be expressed as a complex phenomenon which directly involves social, psychological, and biological aspects. These aspects are related to each other and influence each other. In the emergence of the social aspect of addiction, we are witnessing the disintegration of appropriate social communication of the addict which can be caused by a problem in the social cognition of individual.

Lack of control over consumption highlights neurocognitive aspects of addiction. Correlates of cognitive control are usually searched in the frontal lobe, especially in the prefrontal area. The proper functioning of prefrontal cortex will equip individuals with the capacity for using of past experience and knowledge for meaningful current behavior and directing the individual to select the responses in the future from the treasury of conduct [13]. In order to search the neural correlates of addictive behavior, there are similarities in addicts' behavior and people with prefrontal damage. For example, increasing desire to achieve immediate rewards to greater but delayed rewards [14], emotional, affective, and social changes [15] were observed in patients with prefrontal damage. Bias toward immediate rewards is called impulsive behavior which is considered as an important characteristic for neural basis of addiction [16]. In addition, lack of the rule change (perseveration), lack of change in response to an already rewarded activity, is related to addiction, since addiction is an inability to change [17]. Perseveration is seen in orbitofrontal damages [18].

These neurological findings about addiction have been followed by brain imaging findings. For example, many imaging studies have shown orbitofrontal disorders in relation to substance abuse [19]. Specialists are connected in many ways in addiction treatment, that among these ways, group therapies and training have found high status. Stress inoculation training, for example, is one way of psychotherapy used recently by specialists [20]. The main issue of this research was to investigate theory of mind in people with opioid dependence and also the effect of group treatment focused on self and others feelings on this category. As a primary objective, two groups with dependence and independence on the ability of theory of mind were compared and in the second part, after 3 months of treatment, two groups of dependencies, experimental group along with other treatments under specific group training and control group which were only treated with routine care, were compared.

\section{Methodology}

The present study is descriptive research in which, in the first part, i.e., comparisons between the two groups of opioid dependence and non-addicted group, it was causal comparative and in the second part, i.e., evaluating the effect of group training, it had two-group pretest-posttest design with a control group. The sample group of dependence in the study was selected among patients attending for treatment of opioid dependence to Bahar rehabilitation and addiction treatment center in Bonab (36 people) and a similar group of 36 people from the entourage of clients in 2012. These kinds of centers are active with the aim of implementation treatment in the three areas of psychological, medical, and family and social interventions. Baron-Cohen's Reading Mind from Eyes Test (RMET) was performed on both groups. In the first stage, two groups of dependence and control group were compared. In the second stage, group of opioid dependence was divided into experimental and control group. For both groups, the most common treatments of the centers were applied for three months which consisted of drug therapy with drugs such as Methadone and Buprenorphine. With the difference that for experimental group was performed specific training focused on awareness of self and others' feelings and emotions in group meetings for three sessions per week. Total of 24 sessions were held in 
8 weeks (Table 1). These groups are referred as skill development groups [21]. After the implementation of these sessions, Baron-Cohen's Reading Mind from Eyes Test (RMET) again was performed on both treatment groups.

Table 1. Social training schedule for experimental group.

\begin{tabular}{ll}
\hline Session & Content of training sessions \\
\hline Session 1 & Plan development/Goal setting \\
Session 2 & The ways of participating in the dialogue \\
Session 3 & How to listen to the person who speaks \\
Session 4 & Skill of listening with patience \\
Session 5 & The skill of understanding the emotional state of the speaker \\
Session 6 & The skill of understanding the emotional state of self \\
Session 7 & The skill of stating own thought about the others' intents \\
Session 8 & Controlling his relation with group through discussion \\
Session 9 & Explanation of himself state in the group \\
Session 10 & Explanation of others' state in the group \\
Session 11 & Reflection of others' view for the group \\
Session 12 & Judging about the atmosphere of the group \\
Session 13- & Review and practice of goals that proposed for 12 first \\
24 & sessions \\
\hline
\end{tabular}

\section{Instrument}

Baron-Cohen's Reading Mind from Eyes Test (RMET): This test was developed by Baron-Cohen et al. in 2001 and since then, it has been used as a neuropsychological test. Baron-Cohen's Reading Mind from Eyes Test (RMET) involves 36 items in which each item is placed on a sheet. Each item of the test comprises of photographs of the eyes and eyebrows region of famous actors in certain emotional states. Below the each image, four words are presented related to different emotional states. Participants are asked to choose the best word which describe emotional topic of each item. Score 1 is given to each correct answer and score 0 to each wrong answer. So, in this test, the highest score is 36 and the lowest is zero. The translated form of the test by Najati, Zabihzade, Maleki, and Mohseni has been used in the studies and the alpha coefficients of the test was reported 0.72 and test-retest coefficient of the sample of 30 students in two weeks was 0.61 [22]. Researchers reported an acceptable validity and good stability for RMET. Khorashad, BaronCohen, Roshan et al. [23] and Prevost, Carrier, Chowne et al. [24], for examples, reported a good validity for the test in samples from different countries.

\section{Results}

To carry out this study, a group of 36 male people were selected among patients attending to Bahar rehabilitation and addiction treatment center as drug dependence group with dependence of opium (opium, heroin, and Shireh). A group similar to the sample group with drug dependence was selected among non-addicted subjects. After comparing the two groups of healthy and dependent in theory of mind variable, dependent group was divided into two groups of control and experimental in order to apply direct variable. Table 1 shows the demographic characteristics of the three groups.

Table 2. Demographic characteristics of the sample groups.

\begin{tabular}{lllll}
\hline Groups & Number & $\begin{array}{l}\text { Consumption } \\
\text { History }\end{array}$ & $\begin{array}{l}\text { Mean } \\
\text { Age }\end{array}$ & $\begin{array}{l}\text { Standard } \\
\text { Deviation }\end{array}$ \\
\hline Experimental Group & 18 & 4.4 & 28.17 & 3.11 \\
Control Group & 18 & 4.6 & 28.82 & 3.68 \\
Total & 36 & - & 83.27 & 6.2 \\
\hline
\end{tabular}

The results of Table 2 indicated that the mean of experimental group in continuous consumption was 4.4, control group 4.6, and the mean age of experimental group was 30.2, control group 29.93 and experimental group 30.25 .

T-test of comparing the means of two independent groups was used in order to compare the two groups of healthy and dependent with 36 people in each one (Table 3).

Table 3. The result of t-test of mean difference of two dependent groups (36 people) and healthy (36 people).

\begin{tabular}{lllll}
\hline Groups & Mean & Standard Deviation & T & Significance Level \\
\hline Addict & 17.2 & 6.27 & 3.25 & 0.036 \\
Healthy & 18.01 & 5.04 & & \\
\hline
\end{tabular}

(Mean difference is significant at the alpha level of 0.05)

The results of Table 3 indicated that the mean of the group of opioid dependence in theory of mind variable or the mean of healthy group has significant difference at the alpha level of 0.05 . The comparison of the mean showed that the ability of substance dependency group in theory of mind is less than the healthy group. Before covariance analysis on data resulted from two stages of mind reading test performance in the pre-test and post-test, homogeneity of variances in two groups of experimental and control was required to be examined. Levene's test was used for this purpose that its results can be seen in Table 4.

Table 4. The results of Levene's test for investigating homogeneity of two groups mean.

\begin{tabular}{llll}
\hline $\begin{array}{l}\text { Levene's } \\
\text { Statistic }\end{array}$ & $\begin{array}{l}\text { Degree of } \\
\text { Freedom 1 }\end{array}$ & $\begin{array}{l}\text { Degree of } \\
\text { Freedom 2 }\end{array}$ & $\begin{array}{l}\text { Significance } \\
\text { Level }\end{array}$ \\
\hline 0.643 & 1 & 34 & 0.372 \\
\hline
\end{tabular}

According to the results of Table 4, the significance level of Levene's test is 0.372 , and, therefore, the assumption of homogeneity of variances was not violated.

For determining the effect of training on theory of mind ability of clients with substance dependency, data obtained from pre-test and post-test of two experimental and control groups were analyzed using one-way analysis of covariance (Table 5).

Table 5. The results of one-way analysis of covariance on mean of the pre and post test scores of experimental and control groups in theory of mind.

\begin{tabular}{llllll}
\hline $\begin{array}{l}\text { Source } \\
\text { Changes }\end{array}$ & $\begin{array}{l}\text { Sum of } \\
\text { Squares }\end{array}$ & $\begin{array}{l}\text { Degree of } \\
\text { Freedom }\end{array}$ & $\begin{array}{l}\text { Mean } \\
\text { Squares }\end{array}$ & F & Sig. \\
\hline Intergroup & 91.2 & 1 & 91.2 & 5.25 & 0.004 \\
Intragroup & 478.8 & 34 & 14.08 & & \\
Total & 5700 & 35 & & & \\
\hline
\end{tabular}

(Mean difference is significant at the alpha level of 0.05) 
The table 5 indicates that the means difference is significant at the alpha level of 0.05 .

\section{Discussion and Conclusion}

The results of the study indicated that theory of mind ability in substance dependence group was weaker than the same group. Theory of mind ability has been studied in many mental disorders. These abnormalities involve range of problems that can have highly social to quite neurological nature. Theory of mind is important since the presence of other is important for person. "Other" for the human and his existence has vital importance. According to Jacques Lacan [25], so who is the "other" that human's dependency on him is more than his link with himself. Because even when he accepts his identity, he again makes him upset. Theory of mind provides part of other's importance. In delusional disorders, schizophrenia, autism, and depression, the importance of other and/or person's misinterpretation or exaggeration of other's mind causes symptoms of the disease.

Mitchell et al. [2] in their study showed that alcoholism leads to social problems caused by problems in the interpretation of the behavior of others. According to the researchers, these problems are related to damage in the theory of mind. The results of this study in consistent with the results of mentioned study showed that theory of mind ability in opiate addicts is weaker than similar healthy people. This indicates that opioid dependence disorders are also related to the theory of mind. However, the fact that substance dependent people had weakness in theory of mind ability before addiction and/or under the influence of substance, they become weak in this ability, are separate issues. But what is related to this research is that dependent people have weakness in theory of mind ability. Neurological changes in parts of the brain, due to long-term use of drugs, are widely proved. Sometimes, these changes can be seen in the areas caused generally by social cognition and specifically in the areas involved in theory of mind.

According to Koob [12], major neuro-biological changes occur following substance use disorders. Brain circuits of cortex-frontal and limbic are involved in addictive behavior. Three important areas involved in addictive behavior affected by substance abuse include: dorsolateral prefrontal cortex, anterior cingulate cortex, and orbitofrontal cortex. All three areas are located in the prefrontal cortex. Recent studies have shown that dorsolateral prefrontal cortex is a key brain area for executive functions, specifically selective attention, monitoring, and planning [17].

As mentioned above, neuronal circuit involved in social attachment is reward circuit which consisted of ventral tegmental area, nucleus accumbens, pallidum, thalamus, and prefrontal-cingulate cortex. Thus, changes in the prefrontal influenced by addiction can lead to affecting the social functions and theory of mind ability. The second part of the research findings indicated that conducting group treatment focused on understanding their own and others' feelings and emotions along with other treatments such as medication, leads to improvement in the theory of mind performance of addicts during the treatment. Volkow, Fowler, and Wang [26] in their presented model believe that addiction is a condition begins with different qualities and high reward value of substances leading to the launch of a series of adaptations in reward, motivation, memory, and control circuits of the brain. These changes lead to the increasing prominence value of substances and loss of inhibitory control against compulsory use of substances [27]. Orbitofrontal cortex and cingulate gyrus are frontal cortical areas which are neuro-anatomically related to limbic structures and more involved in addiction. These areas are activated during periods of euphoria, the desire for substances, consumption and withdrawal. These areas involved in high-level cognitive functions and motivational functions [28].

Addiction leads to cognitive changes, particularly in the executive functions of the frontal lobe of the brain [17]. Addiction, for example, causes stimulus associated with substance use, allocate attentional resources [29]. When in the withdrawal period, attentional resources are taken from stimulant substances, these resources can be focused on other important subjects. In human, lateral prefrontal cortex is responsible for maintaining online multisensory information convergent [13]. On the other hand, prefrontal-cingulate cortex is one of the important areas involved in social cognition (theory of mind is part of it) and also in addiction. Thus, it seems that, in particular, interventions to reduce the reward value of substances, interventions to increase the non-substance reinforces, interventions to weaken learned responses to substances, and interventions to strengthen the control and inhibition of the frontal lobe (that the prefrontal area has sublimation effects on default functions of other parts of the frontal) [30] can lead to changes in different brain functions.

So medication, cognitive behavioral therapy, and group treatment can lead to devaluation of substances reward, increasing the non-substance reinforces, weaken learned responses to substances, and strengthen monitoring and inhibition of the frontal lobe. Generally, social relations and particularly, group treatment can cause prominence of social strengthen. On the other hand, group treatment focused on the awareness of self and others can, as a reinforcing matter, lead to increase the mind reading ability and also neural devoted resources to strengthening related to substance use can involve in strengthening related to social relations.

\section{References}

[1] Premack, D. \& Woodruff, G., (1978). Does the Chimpanzee have a theory of mind? The Behavioural Brain Sciences, 1, 515-526.

[2] Mitchell, I. J., Beck, S. R., Boyal, A., Edwards, V. R. (2011). Theory of mind deficits following acute alcohol intoxication. Eur Addict Res., 17 (3), 164-168.

[3] Green, M., \&Leitman, D. (2008). Social cognition in schizophrenia. Schizophrenia Bulletin, 34, 670-672. 
[4] Charlton, B. (2003). Theory of mind delusions and bizarre delusions in an evolutionary perspective: psychiatry and the social brain. In M. Brune, H. Ribbert\& W. Schiefenhovel (Eds.). The Social Brain - Evolution and Pathology. John Wiley \& Sons: Chichester, 315-338.

[5] Whiten, A. (2000), Social complexity and social intelligence. Novartis Foundation Symposium, 223, 185-196.

[6] Dunbar, R. (2003). The social brain: Mind, language, and society in evolutionary perspective. Annual Review of Anthropology, 32, 163-181.

[7] Allman, J. M., Hakeem, A., Erwin, J. M., Nimchinsky, E., \& Hof, P. (2001). The anterior cingulate cortex: The evolution of an interface between emotion and cognition. Ann N Y AcadSci, 935, 107-17.

[8] Frith, C., \& Frith, U. (2005). Theory of Mind. Current Biology, 15 (17), 644-645.

[9] Thirion- Marissiaux, A. F., Nader-Grosbois, N. (2008). Theory of mind "emotion", Developmental characteristics and social understanding in children and adolescents with intellectual Disabilities. Research in Developmental Disabilities, 29, 414 430.

[10] Krah, S., Paulus, F., Modden, M., Kircher, T. (2010). The rewarding nature of social interactions. Frontiers in Behavioral Neuroscience, 4 (22), 1-3.

[11] Insel, T. (2003). Is social attachment an addictive disorder? Physiological Behavior, 79, 351-357.

[12] Koob, G. F. (2006). The neurobiology of addiction: A neuroadaptational view relevant for diagnosis. Addiction, 101, (1), 23-30.

[13] Stuss, D. T, Gallup, G. G. Jr., Alexander, M. P. (2001). The frontal lobes are necessary for 'theory of mind'. Brain, 124, 279-86.

[14] Berlin, H. A., Rolls, E. T., Kischka, U. (2004). Impulsivity, time perception, emotion and reinforcement sensitivity in patients with orbitofrontal cortex lesions. Brain, 127, 110826.

[15] Bechara, A. (2005). Decision making, impulse control and loss of willpower to resist drugs: A neurocognitive perspective. Nat Neuroscience, 8, 1458-63.

[16] Reynolds, B. (2006). A review of delay-discounting research with humans: relations to drug use and gambling. Behav Pharmacol, 17, 651-67.

[17] Crews, F. T., Boettiger, C. A. (2009). Impulsivity, frontal lobes and risk for addiction. Pharmacology, Biochemistry and Behavior, 93, 237-247.

[18] Tait, D. S., Brown, V. J. (2007). Difficulty overcoming learned non-reward during reversal learning in rats with ibotenic acid lesions of orbital prefrontal cortex. Ann NY AcadSci, 1121, 407-20.

[19] Boettiger, C. A., Mitchell, J. M, Tavares, V. C., Robertson, M., Joslyn, G. D. 'Esposito, M., et al. (2007). Immediate reward bias in humans: Fronto-parietal networks and a role for the catechol-O-methyltransferase 158 (Val/Val) genotype. $J$ Neurosci, 27, 14383-91.

[20] Tarkhan, M. (2012). Effectiveness of group stress inoculation training (SIT) on social self-efficacy and social anxiety of withdrawal addicts. Social Psychology Research Quarterly, 2 (5), 69-79.

[21] Gitterman, A. \& Salmon, R. (2009). Encyclopedia of Social Work with Groups. Routledge, New York and London.

[22] Zabihzadeh, A., Najati, V., Maleki, G., Darvishilord, M., \&Radfar, F. (2013). The study of the relationship between mind reading ability and big five factor of personality. Advances in Cognitive Science Quarterly, 14 (1).

[23] Khorashad, B. S., Baron-Cohen, S., Roshan, G. M., Kazemian, K., Khazai, L., Aghili, Z., Talaei, A., Afkhamizadeh, M. (2015). The "Reading the Mind in the Eyes" Test: Investigation of Psychometric Properties and Test-Retest Reliability of the Persian Version. J Autism Dev Disord., 45: 2651-2666.

[24] Prevost, M., Carrier, M. E., Chowne, G., Zelkowitz, Ph. Lawrence Joseph, L., and Ian Gold, I. (2013). The Reading the Mind in the Eyes test: validation of a French version and exploration of cultural variations in a multi-ethnic city. Cognitive Neuropsychiatry, 10, 1-16.

[25] Richard, B. (2001). Freud as philosopher: Metapsychology after Lacan. Routledge Publication. UK.

[26] Volkow, N. D. Fowler, J. S. and Wang, G. J. (2003) The addicted human brain: insights from imaging studies. The Journal of Clinical Investigation, 111 (10).

[27] Volkow, N. D., et al. (2002). Brain DA D2 receptors predict reinforcing effects of stimulants in humans: replication study. Synapse, 46, 79-82.

[28] Goldstein, R. Z. Volkow, N. D. (2002). Drug Addiction and Its Underlying Neurobiological Basis: Neuroimaging Evidence for the Involvement of the Frontal Cortex. Am J Psychiatry, $159,1642-1652$.

[29] Enayat, J., Javanmard, Gh., Mamagani, J. (2012). Comparison OF attentional bias toward opium in withdrawal and dependent people among the clients to health clinics and the community members of Narcotics Anonymous. Quarterly of Addiction Studies, 6 (23), 27-37.

[30] Kreek, M. J., LaForge, K. S., \& Butelman, E. (2002). Pharmacotherapy of addictions. Nat. Rev. Drug Discov, 1, 710-726. 